ArtefaCToS. Revista de estudios de la ciencia y la tecnología

eISSN: $1989-3612$

Vol. 9, No. 1 (2020), 2. a Época, 131-158

DOI: https://dx.doi.org/10.14201/art202091131158

\title{
Las Ciencias de la Comunicación desde el realismo científico: El problema de la complejidad y las noticias falsas (fake news) ${ }^{*}$
}

\section{Communication Sciences from Scientific Realism: The Problem of Complexity and Fake News}

\section{María José ARROJO}

Facultad de Ciencias de la Comunicación y

Centro de Investigación de Filosofía de la Ciencia y la Tecnología, UDC, España maria.jose.arrojo@udc.es

Recibido: 30/03/2020. Revisado: 04/04/2020. Aceptado: 10/04/2020

\section{Resumen}

El estudio de las Ciencias de la Comunicación desde el realismo científico pone de relieve el carácter dual de estas disciplinas. Son Ciencias Sociales y también Ciencias de lo Artificial. Esta dualidad incide al tratar la objetividad y la verdad, para evitar las noticias falsas (fake news). Vista desde las Ciencias Sociales, la objetividad lleva a una realidad independiente de la mente que la conoce - permite hablar de "hechos" - y la verdad se entiende principalmente en términos epistemológicos (contenidos en correspondencia con lo real). Considerada desde las Ciencias de lo Artificial, donde la objetividad está vinculada a la acción y la verdad práctica, prevalece un componente pragmático, pues ahora descansa en diseños orientados a objetivos, procesos y resultados.

En el primer caso, las cuestiones sobre la objetividad y la verdad llevan directamente a las dimensiones semántica, epistemológica y ontológica, donde el realismo científico puede proporcionar criterios para poder enfocar la práctica profesional periodística. En el segundo caso, al ampliar las posibilidades humanas — sobre todo mediante el uso de Internet-, se incrementa la complejidad de los fenómenos comunicativos. Este entorno de acción y verdad práctica resulta

\footnotetext{
"Este análisis se desarrolla en el marco del Proyecto de Investigación FFI2016-79728-P del Ministerio de Economía, Industria y Competitividad (AEI). Este texto fue preparando durante una estancia de investigación en la Universidad de Bolonia.
} 


$$
\begin{gathered}
\text { María José Arrojo } \\
\text { Las Ciencias de la Comunicación desde el realismo científico: El problema de la complejidad } \\
\text { y las noticias falsas (fake news) }
\end{gathered}
$$

más difícil de establecer desde el realismo científico y requiere un componente de pragmatismo.

Palabras clave: social; artificial; objetividad; verdad; hechos.

\begin{abstract}
The study of the communication sciences from the perspective of scientific realism highlights the dual nature of these disciplines. They are social sciences and also sciences of the artificial. This duality has an impact when dealing with objectivity and truth, in order to avoid false news. Seen from the social sciences, objectivity leads to a reality independent of the mind that knows it —it allows us to speak of "facts" - and truth is understood mainly in epistemological terms (contents in correspondence with what is real). Considered from the sciences of the artificial, where objectivity is linked to action and practical truth, a pragmatic component prevails, since it now rests on designs oriented to objectives, processes and results.

In the first case, issues about objectivity and truth lead directly to the semantic, epistemological and ontological dimensions, where scientific realism can provide criteria to focus professional journalistic practice. In the second case, by expanding human possibilities - especially through the use of the Internet-, the complexity of communicative phenomena increases. This environment of action and practical truth is more difficult to establish from scientific realism and requires a component of pragmatism.
\end{abstract}

Keywords: social; artificial; objectivity; truth; facts.

\title{
1. Las Ciencias de la Comunicación ante el realismo científico y la compleji- dad del fenómeno comunicativo
}

$\mathrm{Al}$ igual que en otras disciplinas científicas, el problema del realismo científico en las Ciencias de la Comunicación se puede abordar desde distintos ángulos. En el actual debate sobre cómo entender el "realismo científico" hay una amplia gama de opciones ${ }^{1}$, pero cabe resaltar varios rasgos que se suelen proponer como componentes habitualmente aceptados: 1) se acepta la objetividad del conocimiento científico, que sirve de base para la aproximación a la verdad; 2) las aportaciones científicas están en la senda de la verdad cuando se ajustan a los fenómenos conocidos, de modo que proporcionan explicaciones fiables sobre fenómenos actuales o hacen predicciones acertadas sobre fenómenos anticipados

\footnotetext{
${ }^{1}$ Véase, a este respecto, la amplia gama de opciones considerada en Gonzalez (2020a).
} 


$$
\begin{gathered}
\text { María José Arrojo } \\
\text { Las Ciencias de la Comunicación desde el realismo científico: El problema de la complejidad } \\
\text { y las noticias falsas (fake news) }
\end{gathered}
$$

sobre la base del conocimiento disponible ${ }^{2}$; y 3) hay un mundo exterior, que es distinto de la mente humana que lo conoce, y ese mundo es inteligible para el investigador que caracteriza sus propiedades.

Hacer investigación científica sobre los fenómenos comunicativos requiere indagar con métodos científicos — cuantitativos o cualitativos - sobre una realidad que, en principio, puede cumplir esos tres rasgos señalados: a) cabe una objetividad en el conocimiento de los fenómenos estudiados, que en este caso tiene que ver con la multiplicidad de medios de comunicación (tanto tradicionales como vía Internet); b) es posible hacer enunciados que, además de describir adecuadamente los fenómenos comunicativos, ofrezcan explicaciones fiables o hagan predicciones correctas respecto del futuro posible $e^{3}$; y c) existe ciertamente un mundo exterior, dotado de propiedades que no son meras construcciones de la mente humana, sino que el investigador reconoce a partir de la información de los profesionales del ramo, quienes buscan hacer inteligible lo acontecido o lo esperado.

Todo esto puede ser abordado en las Ciencias de la Comunicación en cuanto que son Ciencias Sociales, de modo que el problema de la verdad puede ser planteado principalmente en términos de correspondencia o adecuación entre los enunciados y los fenómenos comunicativos descritos, que sirven de base para explicaciones o predicciones. Pero las Ciencias de la Comunicación son Ciencias duales, de modo que también son Ciencias de lo Artificial (González, 2008), que amplían las posibilidades humanas; $y$, más en concreto, que son Ciencias de Diseño (González, 2007, y Arrojo 2015a, 2015b, y 2017).

Este componente construccionista complica el problema de la objetividad y la verdad en este campo temático, puesto que las Ciencias de la Comunicación se constituyen como Ciencias Aplicadas y buscan entonces dar soluciones a problemas concretos que han sido seleccionados. Al ser Ciencias de Diseño, las Ciencias de la Comunicación dependen de objetivos que, a través de procesos, buscan llegar a resultados buscados. Luego el tipo objetividad y verdad pasa, en este caso, a estar en el terreno de la práctica. Este rasgo se aprecia mejor si se considera a los medios de comunicación en el contexto de las novedades introducidas mediante el uso de Internet (Küng, Picard, y Towse, 2008) donde aumenta la complejidad estructural y dinámica, que está propiciada por las Ciencias de la Comunicación cuando buscan creatividad científica (Gonzalez y Arrojo, 2019).

Enfocar desde la práctica cuestiones sobre la objetividad y la verdad comporta, en principio, aceptar el pragmatismo en algún grado, que acompańa entonces

\footnotetext{
${ }^{2}$ El énfasis en el papel de la predicción con éxito como elemento en favor de la objetividad científica - y, por tanto, en la línea del realismo científico- es algo defendido por el realismo pragmatista. Cfr. Gonzalez (2020b)

${ }^{3}$ Como expone Nicholas Rescher (1998), las predicciones pueden ser correctas cuando se enuncian, pero solo son verdaderas cuando el fenómeno predicho se cumple.
} 


$$
\begin{gathered}
\text { María José Arrojo } \\
\text { Las Ciencias de la Comunicación desde el realismo científico: El problema de la complejidad } \\
\text { y las noticias falsas (fake news) }
\end{gathered}
$$

al realismo científico. Por un lado, es una objetividad que, sobre la base de un diseño, incluye componentes construidos para dar respuesta a un problema concreto. Por otro lado, la verdad práctica tiene que ver con la acción que acierta a resolver un problema más que con la adecuación de una descripción respecto de un fenómeno (cfr. Kitcher, 2011), actual o futuro. Ciertamente no es lo mismo un fenómeno descrito por un periodista, que un investigador analiza para ver su adecuación o no a lo real, y un fenómeno deliberadamente buscado para ampliar las posibilidades humanas, cuyo acierto práctico hay que probar en razón de conseguir o no la meta buscada y cómo lo logra.

Luego, tenemos dos grandes tipos distintos de fenómenos comunicativos que inciden a la hora de tratar las noticias falsas (fake news). (i) Los fenómenos comunicativos originados por una necesidad humana de comunicación — generalmente asociada al uso del lenguaje-, que constituye también uno de los soportes sobre los que se construye la vida en sociedad ${ }^{4}$. (ii) Los fenómenos comunicativos derivados del carácter artificial de la actividad comunicativa, que han crecido exponencialmente en las últimas décadas. Esos fenómenos comunicativos están construidos sobre la base de la creatividad científica y el soporte procedente de la innovación tecnológica, que incluye el uso de la Inteligencia Artificial (Arrojo, 2017).

Los dos grandes tipos distintos de fenómenos comunicativos se encuentran en la Red de redes. De una parte, está el lenguaje ordinario - los textos legibles-y el lenguaje audiovisual, que buscan poder acercarse a lo real. Su contenido - sea semántico o audiovisual - puede ser potencialmente verdadero o falso. En este sentido, las Ciencias de la Comunicación, en cuanto que Ciencias Sociales, tienen ahí una materia prima para la investigación, pues cada uno de esos fenómenos comunicativos atañe de un modo u otro a la vida social. Ahora, a diferencia de los fenómenos comunicativos tradicionales, las barreras espacio-temporales se han eliminado.

Mientras tanto, de otra parte, está la vertiente artificial de los fenómenos comunicativos debidos a Internet, donde la comunicación es dinámica y también lo son los avances científicos y tecnológicos que expanden sus posibilidades. Así, las Ciencias de la Comunicación afrontan ahí un incremento de la complejidad en los fenómenos comunicativos, debido a los nuevos diseños comunicativos, que están modificando el tipo de comunicación interpersonal y la propia vida en sociedad.

Los nuevos diseños cambian el cuadro respecto de etapas anteriores: a) esos diseños comunicativos están mediados por los soportes tecnológicos disponibles o alcanzables; b) los agentes tienen nuevos objetivos y cuentan con capacidad de distribuir noticias, pues no son sólo los medios de comunicación los transmisores

\footnotetext{
${ }^{4}$ Para Giuliano Gaeta (1966), el nacimiento de la necesidad informativa se remonta a la comunidad primitiva y acompaña a la construcción de la vida en sociedad.
} 
de enunciados, sino que está al alcance de cualquier ciudadano conectado a la Red; c) cambian los procesos, puesto que se han multiplicado los soportes a través de los que se pueden trasladar tanto las informaciones como otras propuestas comunicativas; y d) hay nuevos resultados, pues los propios contenidos comunicativos también han evolucionado en su formato, adaptándose a fines diversos.

Cabe afrontar el aumento de complejidad de los fenómenos comunicativos a partir del marco filosófico-metodológico proporcionado por el realismo científi$\mathrm{co}^{5}$. Ese enfoque es más nítido para el caso de las Ciencias de la Comunicación que, como es habitual en las Ciencias Sociales, se plantea que, a través del conocimiento que se expresa mediante el lenguaje, es posible llegar a la verdad, esto es, que se puede reflejar lo real de una manera fidedigna o, al menos, que cabe ofrecer enunciados próximos a la verdad (verosimilitud). A este respecto, a pesar del alto grado de complejidad que acompańa a los fenómenos comunicativos, la Ciencia puede proporcionar criterios para poder discernir entre un contenido verdadero y el bulo deliberado o las noticias falsas.

Este es el plano que, habitualmente, se designa como verdad epistemológica, donde se asume que hay verdad cuando se da una correspondencia entre lo enunciado y lo real extramental. Mientras tanto, la verdad práctica de las Ciencias de la Comunicación, en cuanto que Ciencias de Diseño, resulta más difícil de establecer. Porque, como ya señaló Herbert Simon, las Ciencias de lo Artificial se centran en sintetizar más que en analizar (Simon, 1996). Es una dimensión práctica de la verdad que se aprecia cuando se constata que se ha seguido la dirección correcta para la finalidad buscada, que la síntesis ha sido acertada.

Como el entorno comunicativo es crecientemente más complejo, de modo que intervienen cada vez más variables, resulta más difícil discernir qué informaciones son verdaderas. Pero tras la "observación" de periodistas y usuarios de redes sociales, las Ciencias de la Comunicación deben desempeñar un papel para el establecimiento de la posibilidad de la verdad y las pautas para su comprobación, de manera que se pueda garantizar a la ciudadanía un acceso a información objetiva y verdadera. Esto lleva implícito que el problema de la verdad no es meramente epistemológico, sino que tiene también componentes semánticos y ontológicos. A su vez, la verdad tiene indudablemente un vector ético en cada una de esas tres manifestaciones: la semántica, la epistemológica y la ontológica.

\footnotetext{
${ }^{5}$ El realismo científico cuenta entre sus formulaciones el realismo semántico, el realismo epistemológico y el realismo ontológico, como expone González (1993). Variantes más recientes de esas formulaciones se encuentran en Gonzalez (2006).
} 


\section{Marco teórico del realismo científico en el ámbito de la Comunicación. Las dimensiones semántica, epistemológica y ontológica de la verdad}

Aspectos de las dimensiones semántica, epistemológica y ontológica de la verdad, que son centrales en el debate sobre el realismo científico, se pueden detectar en la práctica profesional de los periodistas y en la visión tradicional de las Ciencias de la Comunicación como Ciencias Sociales. Pero también esas dimensiones de interés para el realismo científico preceden a la "cientificación" de la práctica profesional ${ }^{6}$, la fase metodológica que da lugar a la configuración actual de las Ciencias de la Comunicación en Ciencias Aplicadas de Diseño y que genera complejidad, tanto estructural como dinámica (González, 2012).

\subsection{Etapas en la trayectoria histórica en la práctica profesional en el ámbito de la Comunicación}

Históricamente, dentro de lo que ha sido la práctica profesional en el ámbito de la Comunicación (sobre todo en prensa), el problema de la objetividad y de la verdad acerca de los fenómenos comunicativos no es algo nuevo. Ciertamente no es una preocupación que surja a raíz de la proliferación de los soportes digitales y el uso masivo de las redes sociales. Una primera etapa se remonta a los siglos $\mathrm{XVIII}^{7}$ y XIX ${ }^{8}$, cuando los periódicos empezaron a consolidarse como medio de comunicación, y llega hasta la I Guerra Mundial. Son elementos que se asocian al derecho a la libertad de prensa. En esa época, la búsqueda de la objetividad iba ligada a la imparcialidad, la independencia y el equilibrio de los periodistas en el momento de elaborar las informaciones (Maras, 2013). Esta objetividad se pone en entredicho con la proliferación de la prensa de masas y los intereses económicos de los editores para hacer sus medios rentables.

La segunda etapa tiene su origen en la I Guerra Mundial, tras el uso de la prensa por parte de ideologías extremistas. Surge así un interés incipiente en las Universidades de Leipzig o Múnich por la realización de un análisis teórico de los medios de comunicación de masas (mass media). Se buscaba elevar el periodismo a la categoría de Ciencia. De este modo, en 1916 se funda en Alemania el Leipziger Institut für Zeintungskunde, que intentaba hacer la Ciencia del Perió-

\footnotetext{
${ }^{6}$ Sobre el concepto de "cientificación" una práctica profesional, cfr. Niiniluouto (1993).

${ }^{7}$ En el artículo XII de la Declaración de Derechos del Estado de Virginia de 1776, se recoge lo siguiente: "That the freedom of the press is one of the greatest bulwarks of liberty and can never be restrained but by despotic governments", The Virginia Declaration of Rights (1776). Posteriormente, la Declaración de los Derechos del Hombre y del Ciudadano de la Revolución Francesa, de 1789, también recoge en su artículo 11 que la libre comunicación de pensamientos y opiniones es uno de los derechos más valiosos del Hombre.

${ }^{8}$ John Bury aseguraba que en ninguna nación la prensa fue verdaderamente libre hasta el siglo XIX: "Nowhere did the Press become really free till the nineteenth century", Bury (1913).
} 
dico bajo la dirección de Karl Bücher?. El reto era un análisis de los fenómenos comunicativos orientado al desarrollo de teorías y la formulación de hipótesis, que sirviera para la preparación en el ejercicio profesional a través de la aplicación de conocimientos y métodos científicos. Paulatinamente, hay una masa crítica de teóricos que empiezan a cientificar la Comunicación. Así, Otto Groth trata de establecer las pautas conceptuales de la práctica periodística y defiende la autonomía científica del saber periodístico ${ }^{10}$. En 1928 el norteamericano Hartley se interesa por una fórmula teórica para comprender la relación entre formulación del mensaje e intencionalidad (Hartley, 1928).

Se asocia entonces la objetividad y la verdad a las teorías científicas que proporcionen conocimiento preciso sobre la realidad que existe. Paralelamente, se ve la necesidad de que los profesionales tengan una formación sólida, de tipo científico, sobre Comunicación. Empieza a reclamarse así un conocimiento riguroso y científico en el ámbito de la Comunicación, que vaya más allá de la mera intuición de los profesionales (Arrojo, 2019). También la objetividad y la verdad tienen un papel en los primeros códigos deontológicos de la profesión. El concepto de objetividad en esta época se asocia al rigor de datos contrastados que deben aportar los profesionales de los medios de comunicación, de tal modo que la objetividad se convierte en el garante de la Ética profesional de los periodistas (Calcutt y Hammond, 2018).

Después, la tercera etapa viene tras el fin de la II Guerra Mundial ${ }^{11}$. Además de los medios escritos, crece la relevancia de los medios audiovisuales. Hay un cambio de perspectiva. Así, para que la información aportada propicie objetividad y conocimiento verdadero, no es suficiente la mera contrastación de datos. Hace falta un contexto interpretativo de esos datos, que permita valorar la fiabilidad del conocimiento ofrecido (Luce y Jessup, 1969, 70-71). Para menguar el nivel de lo subjetivo, se distingue progresivamente entre datos, información y conocimiento $^{12}$.

\footnotetext{
${ }^{9}$ Para ampliar la información sobre este departamento, véase Universität Leipzig. Disponible en: https://www.sozphil.uni-leipzig.delinstitut-fuer-kommunikations-und-medienwissenschaft/institut/ ueber-uns/geschichtel

${ }^{10}$ Otto Groth publica entre 1910 y 1928 Die Zeitung, una obra en cuatro volúmenes, que constituye un trabajo enciclopédico sobre el periodismo. Cfr. Groth (1928). No obstante, su reflexión más estructurada, en la que fundamenta la autonomía de la Ciencia periodística es Die unerkannte Kulturmacht. Grudlegung der Zeitungswissenschaft. Cfr. Groth, Otto (1972).

${ }^{11}$ La Declaración Universal de Derechos Humanos recoge, entre sus principios, los siguientes que tienen relación con la información: (i) libertad de acceso a los hechos, a las fuentes de la noticia; (ii) libertad de circulación de las noticias; (iii) libertad de constitución de entes dedicados a la información; (iv) libertad de difusión pública de las informaciones; y (v) derecho a la reglamentación jurídica de esas libertades que especifiquen también las responsabilidades. Véase Declaración Universal de Derechos Humanos (1948).

${ }^{12}$ Acerca de la distinción entre "datos", “información” y “conocimiento” véase Rescher (1999).
} 


$$
\begin{gathered}
\text { María José Arrojo } \\
\text { Las Ciencias de la Comunicación desde el realismo científico: El problema de la complejidad } \\
\text { y las noticias falsas (fake news) }
\end{gathered}
$$

Hay una cuarta etapa, que abarca finales del siglo XX y principios del siglo XXI, pues los fenómenos comunicativos han adquirido una nueva dimensión con la irrupción de la Tecnología digital y la proliferación de nuevos soportes comunicativos, como las redes sociales, y motores de búsqueda, como Google o Yahoo. Las características del nuevo entorno artificial de carácter digital y la proliferación de nuevos diseńos comunicativos han aumentando exponencialmente la actividad comunicativa y, con ella, la posibilidad de difundir noticias falsas a nivel global ${ }^{13}$, hasta el punto de que puede llegar a poner en peligro la propia sostenibilidad de la democracia.

\subsection{Contribución del realismo científico ante la nueva situación}

El realismo científico permite afrontar la nueva situación, donde hay nuevos tipos de lenguaje comunicativo, el conocimiento de los fenómenos comunicativos va asociado a un claro predominio de la inmediatez, con la interacción de numerosos agentes, y ha cambiado el marco ontológico. En efecto, lo social - campo tradicional de los fenómenos comunicativos- está ahora completamente mediado por lo artificial: mediante la Red de redes y el uso de las Tecnologías de la Información y la Comunicación. Lograr ofrecer lo objetivo y lo verdadero en los fenómenos comunicativos es entonces un auténtico reto científico.

Para el caso de las Ciencias de la Comunicación, cabe aceptar una serie de propuestas del realismo científico (González, 1993, 18), planteamientos habitualmente pensados para otras disciplinas. (i) Desde el punto de vista ontológico, existe una realidad independiente de la mente -individual o colectiva- que se acerque a ella para describirla, darle explicación o plantear una predicción. Esto permite que los profesionales de la Comunicación puedan hablar de "hechos" como un fenómeno real, algo que existe con independencia de las personas o grupos que estén conociendo. Esta objetividad es compatible con la existencia de diversas perspectivas para conocer el hecho, en la medida en que el fenómeno - suceso o evento - es poliédrico (como la caída del muro de Berlín, el derrumbamiento de las Torres Gemelas o la epidemia de coronavirus). La aceptación de "hechos", entendidos de esta forma, es clave para erradicar las noticias falsas, pues las fake news se apoyan de ordinario en lo que es ontológicamente falso ${ }^{14}$.

\footnotetext{
${ }^{13}$ Un estudio reciente del MIT Initiative on the Digital Economy mostró que las noticias falsas tienen un $70 \%$ más de probabilidades de ser compartidas y creídas por quien las lee que las noticias verídicas. Según este estudio, la verdad tarda aproximadamente seis veces más tiempo que la mentira en alcanzar a 1.500 personas. Para ampliar información sobre este estudio véase Vosoughi, Roy y Aral, (2018).

${ }^{14}$ En su última etapa filosófica, Popper aceptó la verdad ontológica como elemento clave de su concepción, que se basaba en la eliminación crítica del error y la refutación de lo falso. Cfr. Popper (1972). La aceptación del mundo externo como independiente de cualquier mente o proceso humano también es otro de los elementos de su propuesta, cfr. Popper $(1974,13)$.
} 
(ii) Esa realidad independiente de la mente que la conoce puede llegar a ser expresada correcta y adecuadamente a través del lenguaje utilizado. Así, los medios de comunicación, tanto por vía de textos como a través de fotografías o imágenes, pueden ofrecer algo verdadero en sentido epistemológico. Esto quiere decir que cabe lograr que lo dicho o lo mostrado sea acorde con lo realmente acontecido, sabiendo que lo real — si tiene complejidad — tiene habitualmente múltiples aspectos a tener en cuenta, de modo que el lenguaje utilizado — sea natural o audiovisual - no permita agotar esa realidad. Esto se puede entender en sentido de "realismo crítico", que no se queda en lo puramente "dado" o lo primero que se presenta al conocimiento ${ }^{15}$. A su vez, está la veracidad de expresar lo realmente pensado o conocido, sin intentar tergiversar o modificar lo que uno mentalmente acepta o sabe. La falta de veracidad hace que, junto a la falsedad expresada, haya ordinariamente una intencionalidad de engañar, lo que lleva a expresar una mentira ${ }^{16}$.

(iii) Epistemológicamente, los agentes que hacen la Ciencia de la Comunicación y los profesionales de los medios de comunicación pueden - y deben- estar formados para aspirar a un conocimiento objetivo, capaz de lograr contenidos verdaderos acerca de los fenómenos descritos, explicados o predichos. Junto a la inteligibilidad de lo real — sean sucesos naturales, eventos sociales o contribuciones artificiales - está la capacidad intelectual de la persona que, dotada de las categorías conceptuales adecuadas, se acerca a lo real y debe posibilitar conocer lo real tal y como es. Esto permite distinguir una información falsa respecto de un bulo intencionado o una noticia falsa.

Ciertamente, hay una serie de posturas alternativas al realismo científico y otras concepciones antagonistas de sus postulados. Con sus respectivos matices, presentan sus objeciones principalmente por motivos semánticos, epistemológicos y ontológicos ${ }^{17}$, pero también lógicos, metodológicos y axiológicos (Gonzalez, 2006). Desde el punto de vista semántico, cuestionan la objetividad del lenguaje. Insisten en la existencia de elementos subjetivos o intersubjetivos que imposibilitan un nexo objetivo entre lenguaje y realidad. Desde una perspectiva epistemológica, los anti-realistas cuestionan que se pueda alcanzar la verdad mediante el conocimiento científico. La sustituyen por la prueba entendida como aserción justificada (Dummett, 1978; cfr. Wright, 1987), o por la mera adecuación empírica, para resaltar la importancia de poder llegar a resolver problemas

\footnotetext{
${ }^{15}$ Esta crítica al mito de lo dado — una postura propia del realismo ingenuo- ha sido realizada desde hace mucho tiempo por la Escuela Finlandesa de Filosofía de la Ciencia cuando se trata de fenómenos sociales, cfr. Tuomela $(1985,1987)$.

${ }^{16} \mathrm{La}$ presencia de la intencionalidad de engañar, que es un rasgo de actividad percibible por los agentes, es lo que distingue el mero error o una captación falsa de un fenómeno de lo constituye una mentira en sentido estricto.

${ }^{17}$ Para ampliar información sobre las alternativas al realismo científico y las posturas antagonistas al realismo, cfr. González (1993 y 2020a).
} 
(Laudan, 1981), o a mostrar empíricamente el contenido de una teoría. En cuanto a la perspectiva ontológica, no admiten que la realidad tenga entidad por sí misma, que sea algo que pueda existir al margen de la propia mente cognoscente. En los planteamientos de relativismo ontológico, consideran que esa realidad está siempre condicionada por factores históricos, sociológicos u psicológicos que impiden un acceso objetivo ${ }^{18}$.

Cuando se pasa del plano de la práctica profesional a la elaboración de Ciencia sobre los fenómenos comunicativos, cabe insistir — como hace Ilkka Niiniluoto- en que existe una realidad con propiedades identificables (un mundo independiente de la mente del observador) y que las teorías científicas deberían proporcionar un conocimiento de ese mundo independiente - no una mera percepción de los fenómenos observables_-, puesto que la Ciencia es una actividad humana buscadora de verdad (truth-seeking). Aceptar esto supone asumir que las teorías científicas — también en el campo de las Ciencias de la Comunicaciónproporcionan conocimiento sobre esa realidad y que la Ciencia progresa hacia teorías más verdaderas. Aunque esto no garantice cualquier conexión fáctica entre la práctica de la Ciencia y que se consiga encontrar la verdad a través de ella (truth-finding) (Niiniluoto, 1987, 155).

Al menos en el campo de las Ciencias de la Comunicación en cuanto que Ciencias Sociales, este planteamiento de Niiniluoto permite apreciar que la práctica del periodismo (prensa escrita, radio, televisión, nuevas plataformas, etc.) no debe quedar reducida a una mera actividad o profesión donde los criterios subjetivos o intersubjetivos dominan por completo el panorama. El realismo científico en las Ciencias Sociales ha de propiciar que hay soporte semántico, epistemológico y ontológico para llegar a lo objetivo, que es la ruta sólida para alcanzar lo verdadero o, al menos, para incrementar la proximidad a la verdad (verosimilitud).

Cabe —a mi juicio — tener criterios para distinguir en esos planos — semántico, epistemológico y ontológico- cuando algo es o no objetivo. A su vez, eso tiene un componente de valor ético, de indudable relevancia social, por el impacto de los medios de comunicación. Porque la verdad es un valor ético, que no se reduce a mero consenso o acuerdo más o menos aceptado por un colectivo o una organización. La verdad como valor ético se pierde cuando los profesionales de los medios y los investigadores de los fenómenos comunicativos no buscan lo objetivo.

\section{La complejidad en las Ciencias de la Comunicación y el problema de la verdad}

Como las Ciencias de la Comunicación tienen carácter dual, tienen una complejidad de origen (Arrojo, 2015a y 2017). Por un lado, como se ha insistido en

\footnotetext{
${ }^{18}$ Esto se aprecia sobre todo en los autores del "giro social” (social turn), cfr. Gonzalez (2006).
} 


$$
\begin{gathered}
\text { María José Arrojo } \\
\text { Las Ciencias de la Comunicación desde el realismo científico: El problema de la complejidad } \\
\text { y las noticias falsas (fake news) }
\end{gathered}
$$

el apartado anterior, se enmarcan dentro de las Ciencias Sociales, puesto que están enraizadas en una necesidad humana y los fenómenos comunicativos tienen constitutivamente una función social. Por otro lado, son Ciencias de lo Artificial, en tanto que trabajan con diseńos orientados a potenciar las posibilidades de la comunicación humana. Es en este ámbito donde el componente científico y el tecnológico de la actividad comunicativa están en interacción constante. Esa interacción forma parte del quehacer como Ciencia Aplicada encaminada a resolver problemas concretos.

Junto a la creatividad de los diseños científicos está la dependencia creciente respecto del componente tecnológico. La Tecnología es un quehacer humano que transforma la realidad de un modo creativo y que da lugar a nuevos artefactos (Gonzalez, 2015), como sucede con la plataforma de Internet, la Red que ha permitido numeroso nuevos diseńos comunicativos. a) Esos artefactos - en particular, los relacionados con la plataforma tecnológica de Internet- inciden en cómo elaborar la Ciencia Aplicada - la resolución de problemas comunicativos concretos- y en la aplicación de la Ciencia, que es el uso de ese conocimiento práctico en contextos específicos ${ }^{19}$. b) Esos artefactos tienen efectos directos en la propia actividad comunicativa, de modo que permite una comunicación mucho más rápida y fluida. Facilitan así un mayor acceso a los contenidos, además de ampliar el campo de los contenidos accesibles. c) Esos artefactos tienen un efecto directo en la sociedad misma, pues hoy cualquier sujeto puede interactuar con la fuente directamente o convertirse en emisor de información para un público potencial muy amplio.

Mediante la primacía de la práctica, derivada de la interacción entre creatividad científica y la innovación tecnológica, el problema de la objetividad y la verdad en las Ciencias de la Comunicación se sitúa en un dominio distinto del descrito antes para las Ciencias Sociales. Prevalece entonces un cierto componente pragmático, dentro de un cuadro filosófico-metodológico que incluye al menos los siguientes elementos: (i) la consideración de las Ciencias de la Comunicación como Ciencias Aplicadas lleva a que se plantea la cuestión de la verdad práctica al hilo de la resolución de problemas concretos; (ii) la aplicación de la Ciencia en contextos de uso específicos, realizada mediante la práctica profesional requiere componentes objetivos, para no caer en la arbitrariedad o el puro subjetivismo; y (iii) en la innovación tecnológica no se reduce a ser un mero soporte sino que influye en los propios contenidos, de modo que puede incluir aspectos que el profesional de la Comunicación puede no controlar y que condicionan directamente su trabajo.

Todo esto comporta complejidad estructural y dinámica, tanto para afrontar los problemas comunicativos como en los propios fenómenos comunicativos,

\footnotetext{
${ }^{19}$ Junto con la distinción entre Ciencia Aplicada y aplicación de la Ciencia, se asume una diferencia conceptual de ambas respecto de la Tecnología. Cfr. Gonzalez (2013).
} 


$$
\begin{gathered}
\text { María José Arrojo } \\
\text { Las Ciencias de la Comunicación desde el realismo científico: El problema de la complejidad } \\
\text { y las noticias falsas (fake news) }
\end{gathered}
$$

como se está viendo con las redes sociales. Su dinámica está en constante evolución y cambio, pues los fenómenos comunicativos no son estáticos (Arrojo, 2015a, 20-19). Dentro de este marco, conseguir dictaminar qué cabe considerar como verdad práctica en el caso de la Ciencia Aplicada no es tarea sencilla. Tampoco lo es poder garantizar objetividad en la aplicación de la Ciencia. Pero sí parece claro la necesidad de la verdad como valor ético. El respeto por la verdad en los agentes - individuales o sociales — que han de aplicar el conocimiento científico en contextos de uso distintos y variables en el tiempo, parece un requisito necesario (Arrojo, 2019).

Parece exigible que las nuevas pautas y cánones comunicacionales sean evaluables desde el punto de vista ético, tanto en sus objetivos como en sus procesos y los resultados buscados. Dentro de este marco ético, no es suficiente con pensar en lo legal. Hay que pensar en lo legítimo. El tamiz de la Ética es imprescindible, porque se están desarrollando algunos tipos de uso que no están penalizados por la ley, pero que no son aceptables desde un punto de vista ético ${ }^{20}$. Así, no todo lo que es legal es ya, de suyo, ético; pero lo ético sí tiene componentes que deberían ser asumidos por lo legal ${ }^{21}$.

También el problema de la objetividad y la verdad en la Comunicación guarda relación con posibles usos y aplicaciones de las Tecnologías en este dominio, lo que puede llevar a apelar al principio de precaución. Esto lleva a pensar en el daño posible que puedan causar esas Tecnologías en función del uso que se haga de ellas. Por ejemplo, el Instituto de investigación OpenAI, en San Francisco, ha desarrollado un algoritmo capaz de traducir textos y responder preguntas. Este algoritmo, que abre un campo de desarrollo importante en distintos ámbitos como el educativo-, tiene también un altísimo potencial para redactar noticias falsas que pueden inducir a una credibilidad elevada por parte de los receptores de los mensajes (Knight, 2019).

A partir de un enfoque filosófico-metodológico de realismo, cabe afirmar que el desarrollo tecnológico de las redes sociales no es de suyo pernicioso. Pero, como se aprecia con el coronavirus actual (covid-19), el tipo de comunicación interpersonal que permite está provocando la proliferación de bulos o noticias falsas con una rapidez y un calado mayor de lo que ocurría a través de la comunicación soportada por los medios de comunicación convencionales. Es una cues-

\footnotetext{
${ }^{20}$ Por ejemplo, se pueden utilizar las redes sociales para enseñar a construir bombas, para fomentar el consumo de contenido pornográfico, o para promover hábitos alimenticios poco saludables, por poner sólo algunos ejemplos. No hay ninguna ley que lo impida, aunque desde un punto de vista ético es más que cuestionable.

${ }^{21}$ La presencia de cierto tipo de programas de televisión de entretenimiento, que permiten la exhibición pública de realidades privadas, puede estar permitida por ley, pero puede ser cuestionable desde un punto de vista ético. Cfr. Arrojo $(2019,17)$.
} 


$$
\begin{gathered}
\text { María José Arrojo } \\
\text { Las Ciencias de la Comunicación desde el realismo científico: El problema de la complejidad } \\
\text { y las noticias falsas (fake news) }
\end{gathered}
$$

tión que ya ha sido estudiada con respecto al uso de Twitter, donde la difusión de lo falso tiene más impacto que la transmisión de lo verdadero ${ }^{22}$.

En cada uno de estos tres niveles -Ciencia Aplicada, aplicación de la Ciencia e innovación tecnológica- hay fines buscados, unos medios utilizados y los resultados obtenidos. Todos ellos pueden ser o no éticos. Sucede que, en el caso de la Comunicación en el entorno digital, las consecuencias éticas no suelen ser puramente individuales sino claramente sociales. Hay, en efecto, un nuevo espacio de conocimiento, de índole virtual, y un nuevo tipo de relaciones humanas, que están moduladas por una instancia artificial, que es la $\operatorname{Red}^{23}$. Para poder luchar contra la propagación de las noticias falsas procedentes de sociedades artificiales, como son las llamadas "redes sociales", es necesario buscar también los valores éticos endógenos asociados a la Comunicación, como la búsqueda de la verdad ${ }^{24}$.

\section{La verdad como valor ético en el contexto de la comunicación digital: No- ticias falsas, posverdad y la comunicación como una acción humana libre}

Otro factor de complejidad es que, mediante la innovación tecnológica, se ha ampliado la capacidad de acceder a la información y también la capacidad de convertirse en emisores, tanto profesionales como ciudadanos. Mediante el soporte de Internet, las redes sociales que descansan sobre la Web se han convertido en una de las principales fuentes de información para millones de ciudadanos en todo el mundo. Pero, a diferencia de los medios de comunicación tradicionales, esas redes sociales no tienen una línea editorial como tal. Surgen de empresas privadas, que tiene intereses concretos, principalmente económicos o ideológicos. Estas empresas son las que desarrollan y programan los algoritmos que deciden qué es noticia o no para millones de individuos en todo el mundo.

Esta falta de inocuidad en el entorno digital empezó a mostrarse en el año 2016 como una amenaza para la propia sociedad o, al menos, el gran público comenzó a ser consciente de ello. Fue el año del referéndum en el Reino Unido sobre el Brexit, y el año de las elecciones presidenciales en Estados Unidos, en las que resultó ganador Donald Trump (Subramanian, 2017). Ese año marcó un an-

\footnotetext{
${ }^{22}$ Los resultados de una investigación del MIT, en la que se analizaron en torno a 126.000 hilos de noticias en Twitter, tuiteados más de 4,5 millones de veces, por unos 3 millones de personas, entre 2006 y 2017, refleja que la verdad tarda aproximadamente seis veces más de tiempo que lo falso en alcanzar a 1.500 personas. Cfr. Vosoughi, Roy, y Aral $(2018,1148)$.

${ }^{23}$ Este nuevo ámbito, distinto del real y diferente de la vida ciudadana, conforma lo que se denomina "tercer entorno" (Echeverría, 1999) o "Infosfera" (Floridi, 2014). En este nuevo entorno se originan también unas nuevas relaciones comunicativas: los usuarios son ahora agentes activos, pues generan contenido propio. No se conforman con el consumo de contenidos "recibidos" (cfr. Levinson, 2012), sino que son coautores de esos contenidos (cfr. Renó, 2011).

${ }^{24}$ Conviene recordar que, para Popper, la verdad no es solo cognitiva: es también un valor ético (cfr. Martínez Solano, 2005).
} 


$$
\begin{gathered}
\text { María José Arrojo } \\
\text { Las Ciencias de la Comunicación desde el realismo científico: El problema de la complejidad } \\
\text { y las noticias falsas (fake news) }
\end{gathered}
$$

tes y un después en el entorno de la comunicación digital, de modo que la verdad como valor ético mostró de nuevo su relevancia en un dominio práctico. El giro respecto del pasado está en los nuevos soportes comunicativos, que propician la facilidad de distribuir noticias falsas. La incidencia social es clara: los estudios realizados con posterioridad a los dos eventos mencionados mostraron cómo la circulación de noticias falsas los meses antes condicionaron el resultado de las consultas (Allcott y Gentzkow, 2017, y Guess, Nyhan y Reifler, 2018).

Precisamente porque los fenómenos comunicativos se basan en la actividad humana libre son susceptibles de ser evaluados éticamente. En el caso de la proliferación de noticias falsas en la Red, que ciertamente repercuten en la sociedad, hay que realizar varias apreciaciones. 1) Un rasgo de la definición de noticias falsas (fake news) es que se prescinde deliberadamente de lo objetivo. Esto en términos realistas supone algo que no depende de mi mente, pero ciertamente es cognoscible para el sujeto humano. 2) Otro rasgo de las noticias falsas es que buscan lo sesgado, mientras que lo verdadero busca lo imparcial, para estar basado en lo objetivo. 3) Las noticias falsas de las redes sociales no meramente muestran una ausencia de correspondencia con lo real, sino que son intencionalmente falsas, como ha sucedido en las dos citas con las urnas antes mencionadas. Más aún, cuando se trata de cuestiones de especial relevancia social, las noticias falsas tratan de cambiar la realidad, enmascararla u ocultarla. Lo hacen mediante enunciados expresados en lenguaje natural o bien a través de lenguaje audiovisual.

Cambian los aspectos semánticos, epistemológicos y ontológicos con las noticias falsas (fake news): a) la verdad semántica es sustituida por una retórica instrumentalizada, que lleva a un uso de las palabras donde la verdad se considera una creación quijotesca; b) la verdad epistemológica se descarta porque, de modo semejante a los sofistas clásicos, la meta es persuadir para lograr ciertas emociones en lugar de mostrar una realidad cognoscible de modo objetivo; y c) la verdad ontológica - lo real extramental que permite distinguir una perla verdadera de una falsa - se descarta, pues se trata de distorsionar intencionalmente la realidad falseándola, de modo que no caben "hechos" sino "construcciones" sustituidas por otras construcciones elaboradas sobre bases distintas.

Debido a sus características, las redes sociales son escenarios idóneos para la difusión las noticias falsas (fake news). En ellas prima lo emocional y cercano sobre lo objetivo e imparcial. Quienes defienden las noticias falsas buscan alterar la percepción de la realidad de forma intencionada, de manera que influya en el comportamiento de la gente o en su toma de decisiones. Las motivaciones de fondo son principalmente políticas, económicas o ideológicas. Luego, el horizonte de las noticias falsas no es informar, sino persuadir o, incluso, engañar deliberadamente para conseguir un fin (Lazer et al., 2018, 1094).

Pero organismos como la Comisión Europea prefieren huir de la expresión noticias falsas (fake news). Considera que es mejor "desinformación", esto es, una "información falsa, inexacta o engañosa, diseñada, presentada y promovida 
intencionalmente para causar daño público o para obtener beneficios particulares" (European Comission, 2018). También se vincula la desinformación con la intención de enmascarar la realidad, de tal modo que los ciudadanos tengan más complicado reconocer la "verdad", si esta está en contra de los intereses del que quiere desinformar (Magallón, 2019).

Parece claro que el problema de las noticias falsas se ha convertido ya en una alarma a nivel internacional. Así, según el informe del Barómetro de confianza de Edelman —un estudio internacional basado en las opiniones de las élites, que se centra en los principios de confianza en los negocios-, el 73\% de las personas encuestadas manifiestan estar preocupadas por el uso de la información falsa como arma (Edelman, 2019). También la ONU en 2017 ha mostrado su preocupación "por el hecho de que la desinformación y la propaganda a menudo se diseñan e implementan con el propósito de confundir a la población y para injerir en el derecho del público a saber" (ONU, 2017). Previamente, el World Economic Forum había identificado la desinformación como una de las amenazas emergentes de la sociedad (Howell, 2013).

Esta intención de ocultar la verdad ha llevado a acuñar el término "posverdad", como un contenido emotivo deliberadamente falso (esto es, una mentira emotiva ${ }^{25}$. Su distancia respecto de lo verdadero, es señalada por Jesús Miguel Flores - que cita a D'Ancona - como algo que aparenta ser verdad es más importante que la propia verdad (D'Ancona, 2017) ${ }^{26}$. Posverdad se usa para la distorsión deliberada de una realidad, de manera que los hechos objetivos influyan menos a la hora de modelar la opinión pública que los llamamientos a la emoción y a la creencia personal. La finalidad es crear y modelar la opinión pública e influir en las actitudes sociales (Fundéu BBVA, 2016).

Prevalecen en la posverdad las emociones. Se considera que, a la hora de tomar decisiones o de formarse una opinión, los estímulos que la gente siente ante algo influyen de una forma mucho más efectiva que los argumentos, datos o estadísticas (Pauner, 2018, 301). En tal caso fenómenos que tienen un claro componente subjetivo, tales como las emociones y los sentimientos, obtienen un estatuto fuerte y se equiparan a la verdad (Del-Fresno-García y Manfredi-Sánchez, $2018,1232)$. Sucede que las noticias falsas tienden a apelar a las emociones más primarias (sorpresa, tristeza, miedo, enfado, etc.) (Vosoughi, Roy, Aral y Sinan, 2018). Se trata, en cualquier caso, de noticias impactantes, llamativas, con ca-

\footnotetext{
${ }^{25}$ Algunos autores que han abordado el concepto de la "posverdad", véase Drezner (2016), Flood (2016), y McIntyre, (2018).

${ }^{26}$ El Diccionario de Oxford eligió el término "posverdad" como palabra del año en 2016. La recoge como "circunstancia en que los hechos objetivos influyen menos en la formación de la opinión pública que los llamamientos a la emoción y a la creencia personal”. El Diccionario de la Real Academia Espańola también la incorporó en diciembre de 2017. La define como "un elemento disruptivo y perturbador que produce un efecto desestabilizador y una respuesta irracional en la sociedad".
} 


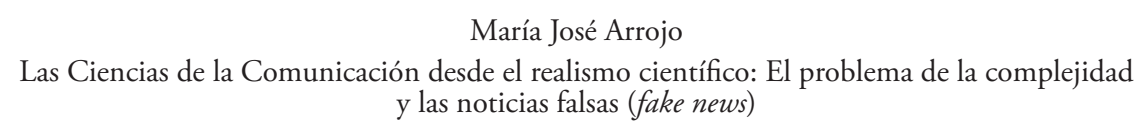

racterísticas de novedad, que son más proclives a ser aceptadas como verdaderas por el usuario. Este fenómeno se explica en términos neurocientíficos, cuando se señala que, al producirse un estímulo primario que nos satisface, el cerebro humano genera una sustancia neurotransmisora denominada dopamina. Está asociada a los procesos adictivos, que nos hace más proclives a interactuar con esa información (Blachnio, Przepiorka, y Pantic, 2016, y Bakir y McStay, 2018).

Junto al contenido transmitido, está el medio utilizado, que también influye en la posverdad y en la aceptación de noticias falsas ${ }^{27}$. Porque en las redes sociales, por las peculiaridades de su diseño, prima la comunicación emocional frente a la racional. Se apela a la respuesta inmediata -igual que en la comunicación oral-, dejando poco tiempo para la reflexión. La emoción está mucho más presente que la razón en este tipo de soportes. Esto puede representar un caldo de cultivo propicio para la difusión de bulos o noticias falsas.

Al prevalecer lo emocional, la mente pone en marcha un proceso que tiende a juzgar automáticamente la veracidad de la información en función de criterios como lo íntimo o familiar (Small y Vorgan, 2009). Los usuarios son más proclives a darle mayor credibilidad a las noticias que comparten con ellos alguien conocido y que confirman sus propias opiniones (Aguirre y Zeta del Pozo, 2017). Esto explica que los rumores o bulos se difundan por la Red de un modo mucho más rápido que las noticias verdaderas. Las 50 noticias falsas más difundidas en Facebook en el ańo 2018, generaron alrededor de 22 millones de interacciones (compartidas, reacciones, comentarios) (Silverman y Pham, 2018).

Se trata de un problema difícil de atajar por dos motivos. El primero está en los nuevos diseños comunicativos de las redes sociales. De ahí deriva un comportamiento sociológico, pues las redes sociales se han convertido ya en una de las principales fuentes de conocimiento para millones de personas. El segundo está en el rastro que cada ciudadano deja en la navegación digital. Esto lleva a una capacidad de conocimiento y segmentación de la audiencia. Sobre esa base, la Inteligencia Artificial puede ofrecer un perfil exacto de la ideología, perfil socioeconómico, cultural, etc., de cada individuo. Así, es posible construir un entorno falso a medida del usuario, donde con la intención de modificar conductas o pensamientos se construye algo falso que acaba teniendo más autoridad que la verdad.

La merma de la búsqueda de la objetividad en el conocimiento y el desapego a la verdad como valor epistemológico y ético para tratar fenómenos comunicati-

\footnotetext{
${ }^{27}$ Craig Silverman, editor del medio digital BuzzFeed, elaboró un trabajo centrado en el seguimiento de noticias falsas. En él muestra cómo las noticias falsas generan mayor repercusión y emoción en la audiencia (engagement) que las noticias publicadas por los medios convencionales. Se compara la repercusión que tuvieron las 20 noticias más populares en la red, publicadas por medios tradicionales o serios ( 7,3 millones de interacciones), con las 20 noticias falsas más virales (8,7 millones de interacciones), tres meses antes de las elecciones a la Casa Blanca en 2016. Cfr. Silverman (2016).
} 
vos tiene claras consecuencias sociales. Así, la actual proliferación de noticias falsas, que están construidas para grupos sociales o perfiles de individuos concretos en redes sociales, que se apoyan en la información aportada por los desarrollos en el ámbito del análisis de datos y la Inteligencia Artificial, tiene efectos nocivos: ataca al propio derecho a la libertad de información, al pluralismo informativo y a la libertad de los ciudadanos de formarse libremente sus opiniones.

Entre las consecuencias sociales de la preferencia por la posverdad y la aceptación de las noticias falsas cabe resaltar tres: (i) pueden obstaculizar que todos los individuos puedan tener acceso a una información contrastada y homogénea sobre las alternativas existentes (una de las bases de la vida en sociedad) (Dahl, 1956, 71); (ii) las posturas en la vida social pueden tornarse más radicales, y (iii) la ausencia de bases objetivas puede dificultar el poder llegar a acuerdos (Pauner, 2018, 299).

\section{La Tecnología al servicio de los valores éticos en la comunicación}

Junto a la creatividad científica está la innovación tecnológica, que —como se ha señalado- es también dual: es soporte para la transmisión de contenidos y, al mismo tiempo, su condicionante principal. Lo primero es instrumental, lo segundo tiene repercusión para los valores éticos de la comunicación. Porque, detrás de la fabricación de noticias falsas puede haber un interés económico, ideológico, político, geoestratégico, etc. Son numerosos los ejemplos de sitios web que generan noticias falsas con apariencia informativa-Spammers- o la existencia de periódicos falsos para conseguir tráfico en la Red (buscan beneficios económicos a través de ingresos publicitarios). Esto es lo que se conoce también como "cascada informativa": noticias falsas que se convierten en virales a través de redes sociales.

También la Tecnología permite filtrar información personal. Es la "burbuja referencial" o la "burbuja de información", que se obtiene a través de los datos que vamos dejando con nuestra actividad en la Red, donde hay pautas de conducta de personas con gustos, opiniones o ideología similar a la nuestra (Dewey, 2016). Los algoritmos los enmarcan como noticias y opiniones con nuestra propia visión del mundo ${ }^{28}$. El entorno digital puede llegar a convertirse así en una caja de resonancia o una cámara de eco (Anthony, 2016), que refleje nuestras propias creencias o idea del mundo ${ }^{29}$. Sobre esta base se puede llegar a un contenido que se difunda como noticia y que se acepte como verdad (Anthony, 2016).

${ }^{28}$ La expresión "filter bubble” aplicada a la información se acunó en 2011. Véase Pariser (2011). ${ }^{29}$ El algoritmo de Google no es completamente neutro. A raíz del despido, por parte de Google, de 18 editores encargados de filtrar noticias verdaderas y noticias falsas, quedó claro que el algoritmo, por sí solo, es incapaz de discernir la totalidad de noticias falsas. En cualquier caso, según unas declaraciones publicadas por The Washington Post: "This is the news Facebook chooses for you to read"; "Facebook has repeatedly trended fake news since firing its human editors". 
Esto significa que estas plataformas tecnológicas orientadas a la transmisión de contenidos no son meras distribuidoras de información. Puede afirmarse que estas compañías tecnológicas no son neutrales si, como sucede en la práctica, filtran la información que puede obtener cada usuario en función de su perfil y de su historial de búsquedas. Se trata de empresas privadas, con claros intereses, que están actuando como "curadores" de contenidos. Más aún, esos datos son fuente de ingresos para los gigantes tecnológicos relacionados con la información y la comunicación.

Desde el punto de vista de los contenidos, los algoritmos en plataformas tecnológicas pueden estar atentando contra la libertad de expresión e información en el entorno digital. Lo hacen cuando imposibilitan o dificultan poder llegar a algunos contenidos sin previa aceptación por los usuarios o cuando los ofrecen con un sesgo a favor de una entidad y, por tanto, al margen de criterios objetivos. Cabe preguntarse hasta qué punto se les podría exigir a estas compañías que explicasen cómo funcionan sus algoritmos para presentarle a cada usuario qué es lo que va a encontrar.

Además de esta vertiente negativa desde el punto de vista ético, hay una faceta positiva del desarrollo científico y el avance tecnológico, que es la lucha contra la desinformación. Tiene lugar de tres maneras: (i) a través del desarrollo de sistemas de detección de noticias falsas; (ii) con el diseño de pautas y modelos de actuación profesionales; y (iii) poniendo en valor a los medios más rigurosos.

Con respecto al primero - la detección de noticias falsas-, los métodos que se está utilizando están basados principalmente en el análisis lingüístico y en la frecuencia de términos utilizados en las noticias falsas (fake news). Se aplican modelos de aprendizaje de máquina o automático (machine learning) y cálculos de semejanza lingüística existente entre las noticias falsas y las verdaderas. Esto permite detectar robots y perfiles dedicados a la producción de noticias falsas. Otra técnica que se está utilizando es el reconocimiento de patrones de difusión. Es decir, un análisis de cómo se comparten los bulos o noticias falsas y qué tienen de distinto en su comportamiento con respecto a las noticias verdaderas.

La cientificación de prácticas profesionales en estos años ha llevado a consensuar un estándar internacional de verificación de la información en el entorno digital, que se recogen en el Código Internacional de Principios de Verificación de Datos, que pueden ayudar en la detección de noticias falsas ${ }^{30}$. También un trabajo de investigación realizado por las Universidades de Michigan y Ámsterdam ha permitido crear un algoritmo que identifica de forma automática contenido falso en la Red, a través de la técnica de comparar diferencias lingüísticas, con una

Véase, Dewey (2016).

${ }^{30}$ La responsabilidad de la redacción de este código ha recaído en The International Fact-Checking Nertwork, una unidad del Poynter Institute dedicado a la protección de las noticias falsas a nivel mundial. 
precisión comparable al quehacer de una persona ${ }^{31}$. No obstante, todavía hay problemas para detectar recursos como la ironía o el humor, o la ambigüedad del lenguaje. Es necesario continuar trabajando en técnicas de análisis de sintaxis profunda, análisis semántico o análisis de la estructura retórica (Blázquez, 2018).

Google posee una biblioteca de consulta para verificadores, periodista e investigadores de 40.000 contenidos comprobados por los principales detectives humanos (fact-checkers) a nivel internacional ${ }^{32}$. También ha puesto a disposición de los profesionales una herramienta denominada Assembler, que es una plataforma experimental para tratar de detectar imágenes manipuladas, que viene a complementar otras herramientas de comprobación ya existentes como TinEye.

Acerca de lo segundo —el diseño de pautas y modelos de actuación— hay un consorcio internacional de medios de comunicación: "The Trust Project", puesto en marcha en 2017. A través de Metodologías de investigación centradas en el análisis del comportamiento de los usuarios en la Red, este consorcio -del que forman parte algunos de los medios internacionales más importantes- ha caracterizado un sistema de 37 indicadores de confianza, para que ayuden a distinguir las noticias más o menos fiables. Los medios que participan en este proyecto han empezado a implantar los ocho indicadores que consideran más importantes ${ }^{33}$ :

1) Mejores prácticas (explicar cuáles son los principios del medio y quién lo financia); 2) experiencia del periodista; 3) tipo de trabajo (género en el que se enmarca la noticia); 4) citas y referencia (identificación de la fuente); 5) métodos de trabajo; 6) noticias de origen local (ayuda a identificar si el medio tiene experiencia en el contexto local en el que surge la noticia); 7) diversidad (compromiso del medio por aportar distintos puntos de vista); y 8) comentarios de los lectores (fomentar espacios para la conversación).

Esto conecta con lo tercero, que es poner en valor a los medios más rigurosos. Porque a través de la cientificación de los nuevos procesos comunicativos observados, se puede empezar a hacer predicción. Es numerosa la literatura científica que certifica cómo los robots de inversión financiera, por ejemplo, han basado parte de su diseńo y de su operativa en los efectos predictivos de la información y del comportamiento del usuario (Blázquez, 2018, y Kogan, Moskowitz y Niessner, 2019). Esto es extrapolable a otros ámbitos y no sólo al económico. Una investigación realizada por Microsoft y el Instituto Technion-Israel de Tecnología ha permitido desarrollar un software que predice cuándo y dónde pueden ocurrir

\footnotetext{
${ }^{31}$ A través de dicho algoritmo el nivel de precisión que se consiguió en la detección de noticias falsas fue de un 76\%, mientras que el nivel de acierto humano alcanzó un 70\%. Para acceder al estudio completo véase Pérez-Rosas, Kleinberg, Lefevre y Mihalcea (2017).

32 Internet pone a disposición de los profesionales el Fact Check Explorer. Disponible en: https:// toolbox.google.com/factchecklexplorer

${ }^{33}$ Los motores de búsqueda y las redes sociales sólo pueden participar como socios externos del programa.
} 
brotes de enfermedades sobre la base de dos décadas de artículos publicados por el New York Times y otra información disponible en la Red (Simonite, 2013).

Otro ejemplo es "Recorded Future", una empresa tecnológica innovadora (start-up) que ha desarrollado un algoritmo capaz de predecir eventos futuros sobre la base de la información almacenada en Internet, combinándola con noticias y eventos actuales. Es decir, la propia innovación tecnológica está trabajando en el camino no sólo de detectar noticias falsas, sino en la posibilidad de crear un software capaz de predecir noticias utilizando la minería de datos en la web. Pero de estas predicciones se puede hacer también un buen o un mal uso. Esto es así porque se puede manipular en el origen, durante el proceso o en el resultado de la información.

Estos proyectos y decálogos que se desarrollan gracias a la cientificación asumen, de facto, la necesidad de la objetividad y la verdad para los fenómenos comunicativos: tratan de luchar contra la profunda desconfianza de la ciudadanía hacia la información que circula por la Red de la que, mayoritariamente, se desconoce su origen y grado de fiabilidad. Frente a este tipo de informaciones falsas ponen en valor aquellas que muestran calidad, transparencia y fiabilidad de los medios que las sustentan.

Ese afán de hacer más visibles las noticias rigurosas, y las medidas correctivas implementadas por algunos agentes, como Google o Facebook, para combatir la desinformación, están empezando a dar los primeros resultados. Hay ya estudios que corroboran que ha disminuido el volumen de noticias falsas que circulan a través de Facebook, por ejemplo ${ }^{34}$. Así pues, la Tecnología puede ayudar a frenar la expansión de las noticias falsas (Bakir y McStay, 2018), pero esa Tecnología está asumiendo el valor de lo verdadero a la hora de hacer el diseño del programa que haga operativa la detección y, en su caso, la eliminación de lo falso.

\section{Consideraciones finales}

El realismo científico, además de los tradicionales campos —el semántico, el epistemológico y el ontológico-, admite también otros ámbitos, como el axiológico (los valores, en general) y el ético (los específicos valores relacionados con la Ética) (Gonzalez, 2006). Cuando el foco va a la verdad en cuanto valor ético, entonces hay que centrarse en los nuevos soportes tecnológicos y en el uso digital en redes sociales, que permitan aplicar los criterios generales en casos concretos. La reflexión debe tener en cuenta tres escenarios: (i) la importancia de la emoción y de las creencias personales en la proliferación de las noticias falsas; (ii) la reflexión necesaria que debería hacerse sobre la barrera que separa lo legal de lo

\footnotetext{
${ }^{34}$ Esta afirmación se respalda en las investigaciones realizadas por los siguientes autores Allcott, Gentzkow y Yu (2019), y Resnick, Ovadya, y Gilchrist (2018).
} 
ético; y (iii) la distinción entre información y opinión y el problema de elevar las opiniones a la categoría de "verdad".

Históricamente, el problema de la circulación de noticias falsas es tan antiguo como la aparición de los medios de comunicación. Casos de mala praxis periodística e informativa han ocurrido siempre. Lo que es completamente nuevo es el volumen de producción de noticias falsas o manipuladas, la forma en la que se producen, la velocidad a la que se distribuyen y el alcance que consiguen (Vosoughi, Roy y Aral, 2018). Los nuevos diseños de comunicación digital han modificado la propia naturaleza de las relaciones y de la comunicación interpersonal.

Cuando los hechos, en cuanto que son lo objetivo contrastable, tienen menos influencia o credibilidad que las emociones y las creencias personales, la verdad pasa a un segundo plano. Lo que prevalece son las opiniones asentadas en sentimientos y emociones, que coinciden además con las ideas personales. El problema estriba en que las opiniones o ideologías se están poniendo en el mismo nivel que los hechos o las informaciones objetivas (Harsin, 2015). Estas nuevas sinergias comunicativas desplegadas en el entorno digital menoscaban la credibilidad de los medios de comunicación, de la propia red de redes y pone en peligro a la propia democracia como sistema político, que necesita la búsqueda de la verdad para poder existir.

Actualmente nos encontramos con contenidos ilícitos circulando por la Red, que se pueden filtrar y retirar, amparándose en bases legales. Pero, también hay contenidos nocivos o dañinos que no son ilegales. Se trata de contenidos que se pueden cuestionar desde un punto de vista ético, pero que no atentan contra la legalidad. Si se les otorga a estas empresas privadas (Google, Facebook, Twitter, etc.) la potestad de discernir entre lo que se puede distribuir y lo que no, a través de etiquetados y de algoritmos, se les estaría dando la potestad de realizar una censura previa, tarea que harían en función de sus propios intereses, que no necesariamente tienen que ser los propios de la ciudadanía ${ }^{35}$.

Otro factor a tener en cuenta, es que es mucho más sencillo comprobar los hechos que las opiniones ${ }^{36}$. Los hechos pueden ser sometidos a prueba o a una constatación objetiva ${ }^{37}$. Las opiniones pueden ser más o menos acertadas, elaboradas conforme a una información más o menos rigurosa, con un mayor o menor sesgo ideológico; pero, con frecuencia, no se puede decir de ellas que sean de suyo

${ }^{35}$ Además, al menos hasta el momento, a los diseños algorítmicos basados en Inteligencia Artificial, les resulta muy difícil detectar y discernir informaciones de opiniones o de sátiras. Para ampliar información sobre el debate ético y legal en el entorno digital. Véase, Teruel (2014).

${ }^{36}$ Para el Tribunal Constitucional español, "las afirmaciones erróneas son inevitables en un debate libre, de tal forma que, de imponerse la verdad como condición para el reconocimiento del derecho, la única garantía de seguridad jurídica sería el silencio”. Véase, Sentencia del Tribunal Constitucional (05/02/1988).

${ }^{37} \mathrm{El}$ hecho de que un incendio haya arrasado un número determinado de hectáreas es fácilmente comprobable. 
"falsas". Así, la difusión de según qué tipo de opiniones, ante según qué tipo de ciudadanía puede juzgarse desde un punto de vista ético, incluso puede calificarse de mejor o peor praxis periodística, pero no se está incurriendo en una ilegalidad. El problema reside cuando se intenta elevar las opiniones a la categoría de "verdad", bien sea por intereses económicos o bien ideológicos (Del-Fresno-García y Manfredi-Sánchez, 2018). Cuando la ideología trata de ejercer algún tipo de autoridad sobre la propia realidad introduce, de facto, una variación ontológica que distorsiona la comunicación de raíz.

Así pues, es muy difícil establecer un límite entre la posible proliferación de las noticias falsas y la libertad de expresión. Incluso puede que los distintos estados tengan puntos de vista diferentes al respecto. Como afirma Cristina Pauner, "no es posible diseñar un algoritmo de la verdad" (Pauner, 2018, 314). Pero la Tecnología sí puede ayudar a detectar y frenar la proliferación de noticias falsas, cuando está programada en territorios ya estudiados.

Probablemente los robots o algoritmos nunca podrán ser la única vía para detectar las noticias falsas, por la dificultad a la hora de captar la ambigüedad de las palabras, los elementos simbólicos o la ironía. A esto se suma la complejidad introducida por la inmediatez de las informaciones. Los programas basados en técnicas de aprendizaje de máquina (machine learning) no disponen de una base de conocimiento que permita identificar noticias verdaderas y falsas ante un hecho novedoso. Pueden existir distintas versiones de los hechos, pues hay diversas perspectivas ante una realidad poliédrica; pero la verdad es algo alcanzable y el procedimiento pasa por tener las pruebas adecuadas al caso estudiado. En la cadena de valor, la inmediatez o la emotividad no deberían estar nunca en posiciones más altas que la verdad (en sus diversas facetas: semántica, epistemológica y ontológica) y esto pasa por la comprobación de los datos.

Pero lo realmente decisivo en la lucha contra la desinformación es el componente humano, cuando asumen la relevancia de lo objetivo y lo verdadero ante los fenómenos comunicativos: (1) esto requiere la formación científica de los profesionales de la Comunicación; (2) hace falta la cientificación de pautas profesionales que permitan identificar pautas de comportamiento de las noticias falsas y establecer procedimientos de actuación; y (3) se precisa el establecimiento de un marco regulatorio que proteja los derechos digitales de los ciudadanos frente al uso que, a partir de diseños de las grandes multinacionales tecnológicas, actualmente hacen los algoritmos de nuestra huella digital. 
Las Ciencias de la Comunicación desde el realismo científico: El problema de la complejidad $\mathrm{y}$ las noticias falsas (fake news)

\section{Referencias bibliográficas}

Aguirre, M. y Zeta del Pozo, Rosa (2017). La verdad en la era de la posverdad. En Rodrigo Cetina, Fernando Gutiérrez, y Loreto Corredoira (eds.), Periodismo de Frontera y Dignidad Humana (pp. 162-180). Madrid: Universidad Complutense. https:// eprints.ucm.es/43869/1/Cetina_Periodismo_de_Frontera_Dignidad_Humana.pdf

Allcott, Hunt y Gentzkow, Matthew (2017). Social media and fake news in the 2016 election. Journal of Economic Perspectives, 31(2), 211-236.

Allcott, Hunt, Gentzkow, Matthew y Yu, Chuan (2019). Trends in the diffusion of misinformation on social media. Research and Politics, abril-junio, pp. 1-8. https:// journals.sagepub.com/doi/pdf/10.1177/2053168019848554

Anthony, Andrew (2016). Inside the hate-filled echo chamber of racism and conspiracy theories. En The Guardian, 18 diciembre de 2016. https://www.theguardian.com/ media/2016/dec/18/gab-the-social-network-for-the-alt-right

Arrojo, María José (2015a). La complejidad como marco de estudio para las Ciencias de la Comunicación. Argos, 32(62), 17-34.

Arrojo, María José (2015b). La investigación de la Comunicación en el marco de la Ciencia Aplicada de Diseño: nuevos parámetros epistemológicos y metodológicos. Informação e Sociedade: Estudos, 25(1), 13-24.

Arrojo, María José (2017). Information and the Internet: An Analysis from the perspective of the Sciences of the Artificial. Minds and Machines, 27(3), 425-448. https://doi.org/10.1007/s11023-016-9413-2

Arrojo, María José (2019). Valores éticos y cambio tecnológico en la comunicación audiovisual: de la ciencia a la Tecnología. Palabra Clave, 22(1), 1-36. https://doi. org/10.5294/pacla.2019.22.1.8

Bakir, Vian y McStay, Andrew (2018). Fake news and the economy of emotions: Problems, causes, solutions. Digital Journalism, 6(2), 154-175.

Blachnio, Agata, Przepiorka, Aneta y Pantic, Igor (2016). Association between Facebook addiction, self-esteem and life satisfaction: a cross-sectional study". Computers in Human Behaviour, 55, 701-705. https://www.kul.pl/files/55/esteemandsatisf.pdf

Blázquez, Manuel (2018). El problema de las noticias falsas: detección y contramedidas. En e-prints in library and information science, pp. 1-18. http:/leprints.rclis. org/33171/1/fakeNews-2018-mblazquez-mexico-FINAL.pdf

Bury, John B. (1913). A History of Freedom of thought. Nueva York: Henry Holt and Company. http://www.gutenberg.org/flles/10684/10684-h/10684

Calcutt, Andrew y Hammond Philip (eds.) (2018). The future of objectivity. En Journalism Studies (pp. 118-146). London-New York: Routledge.

Dahl, Robert (1956). A preface to democratic theory. Chicago-Londres: The University of Chicago Press. 
María José Arrojo

Las Ciencias de la Comunicación desde el realismo científico: El problema de la complejidad y las noticias falsas (fake news)

D'Ancona, Matthew (2017). Post-Truth: The New War on Truth and How to Fight Back. London: Ebury Press.

Declaración Universal de Derechos Humanos (1948). https://www.un.org/es/universaldeclaration-human-rights/

Del-Fresno-García, Miguel y Manfredi-Sánchez, Juan L. (2018). Politics, hackers and partisan networking. Misinformation, national utility and free election in the Catalan independence movement. El professional de la información, 27(6), 12251238.

Dewey, Caitlin (2016). 98 personal data points that Facebook uses to target ads to you. En The Washington Post, 19 de agosto de 2016. https://www.washingtonpost.com/ news/the-intersect/wp/2016/08/19/98-personal-data-points-that-facebook-uses-totarget-ads-to-youl

Drezner, Daniel W. (2016). Why the post-truth political era might be around for a while. En The Washington Post, 16 de junio de 2016. https://www.washingtonpost. com/posteverything/wp/2016/06/16/why-the-post-truth-political-era-might-bearound-for-a-whilel

Dummett, Michael (1978). Truth and other Enigmas. Londres: Duckworth.

Edelman (2019). Trust Barometer Global Report. https://www.edelman.com/sites/g/files/ aatuss191/files/2019-02/2019_Edelman_Trust_Barometer_Global_Report.pdf

Echeverría, Javier (1999). Los señores del aire: telépolis y el tercer entorno. Barcelona: Destino.

European Comission (2018). A multi-dimensional approach to disinformation. Report of the independent High level Group on fake news and online disinformation. https:// ec.europa.euldigital-single-marketlen/news/final-report-high-level-expert-group-fakenews-and-online-disinformation

Flood, Alison (2016). Post-truth named word of the year by Oxford dictionaries. En The Guardian, 15 de noviembre de 2016. https://www.theguardian.com/books/2016/ nov/15/post-truth-named-word-of-the-year-by-oxford-dictionaries

Flores, Jesús M. (2019). Inteligencia artificial y periodismo: diluyendo el impacto de la desinformación y las noticias falsas a través de los bots. Doxa.comunicación, 22, 197-212.

Floridi, Luciano (2014). The fourth revolution: How the infosphere is reshaping human reality. Oxford: Oxford University Press.

Fundéu BBVA (2016). Posverdad mejor que post-verdad. https://www.fundeu.es/ recomendacion/post-truth-post-verdad-posverdadl

Gaeta, Giuliano (1966). Storia del Giornalismo. Milán: Vallardi.

González, Wenceslao J. (1993). El realismo y sus variedades: el debate actual sobre las bases filosóficas de la Ciencia. En Alberto Carreras (ed.), Conocimiento, Ciencia y Realidad (pp. 11-58). Zaragoza: Seminario Interdisciplinar de la Universidad de Zaragoza-Ediciones Mira. 
González, Wenceslao J. (2006). Novelty and Continuity in Philosophy and Methodology of Science. En Wenceslao J. Gonzalez y Jesús Alcolea (eds.), Contemporary Perspectives in Philosophy and Methodology of Science (pp. 1-28). A Coruña: Netbiblo.

González, Wenceslao J. (2007). Configuración de las Ciencias de Diseño como Ciencias de lo Artificial: Papel de la Inteligencia Artificial y de la racionalidad limitada. En Wenceslao J. Gonzalez (ed.), Las Ciencias de Diseño: Racionalidad limitada, predicción y prescripción (pp. 41-69). A Coruńa: Netbiblo.

González, Wenceslao J. (2008). La televisión interactiva y las Ciencias de lo Artificial. En Arrojo, María José, La configuración de la televisión interactiva: De las plataformas digitales a la TDT (pp. xi-xvii). A Coruńa: Netbiblo.

González, Wenceslao J. (2012). Las Ciencias de Diseño en cuanto Ciencias de la Complejidad: Análisis de la Economía, Documentación y Comunicación. En Wenceslao J. Gonzalez (ed.), Las Ciencias de la Complejidad: Vertiente dinámica de las Ciencias de Diseño y sobriedad de factores (pp. 7-30). A Coruña: Netbiblo.

Gonzalez, Wenceslao J. (2013). The Roles of Scientific Creativity and Technological Innovation in the Context of Complexity of Science. En Wenceslao J. Gonzalez (ed.), Creativity, Innovation, and Complexity in Science (pp. 1-40). A Coruña: Netbiblo.

Gonzalez, Wenceslao J. (2015). On the Role of Values in the Configuration of Technology: From Axiology to Ethics. En Wenceslao J. Gonzalez (ed.), New Perspectives on Technology, Values, and Ethics: Theoretical and Practical, Boston Studies in the Philosophy and History of Science (pp. 3-27). Dordrecht: Springer.

Gonzalez, Wenceslao J. y Arrojo, María José (2019). Complexity in the Sciences of the Internet and its Relation to Communication Sciences. Empedocles: European Journal for the Philosophy of Communication, 10(1), 15-33. https://doi.org/10.1386/ ejpc.10.1.15_1

Gonzalez, Wenceslao J. (2020a). Novelty in Scientific Realism: New Approaches to an Ongoing Debate. En Wenceslao J. Gonzalez (ed.), New Approaches to Scientific Realism. Boston-Berlín: De Gruyter.

Gonzalez, Wenceslao J. (2020b). Pragmatic Realism and Scientific Prediction: The Role of Complexity. En Wenceslao J. Gonzalez (ed.), New Approaches to Scientific Realism. Boston-Berlín: De Gruyter.

Groth, Otto (1928). Die Zeitung Ein System Der Zeitungskunde. Germany: Bensheimer.

Groth, Otto (1972). Die unerkannte Kulturmacht. Grudlegung der Zeitungswissenschaft. Berlín: Walter de Gruyter.

Guess, Andrew, Nyhan Brendan, y Reifler, Jason (2018). Selective exposure to misinformation: Evidence from the consumption of fake news during the 2016 US presidential campaign, Working paper. En European Research Council. https:// apo.org.au/sites/default/files/resource-files/2018/01/apo-nid126961-1162776.pdf 
Las Ciencias de la Comunicación desde el realismo científico: El problema de la complejidad y las noticias falsas (fake news)

Harsin, Jayson (2015). Regimes of Posttruth, Postpolitics and Attention Economies. Communication, Culture and Critique, 8(2), 327-333.

Hartley, Ralph V. (1928). Transmission of Information. Bell System Technical Journal, 7(3), 535-563. https://onlinelibrary.wiley.com/doilabs/10.1002/j.1538-7305.1928. tb01236.x

Howell, Lee (2013). Digital wildfires in a hyperconnected world. WEF report. https://reports.weforum.org/global-risks-2013/risk-case-1/digital-wildfires-in-ahyperconnected-world/

Kitcher, Philip (2011). Scientific Realism: The Truth in Pragmatism. En Wenceslao J. Gonzalez (ed.), Scientific Realism and Democratic Society: The Philosophy of Philip Kitcher, Poznan Studies in the Philosophy of the Sciences and the Humanities (pp. 171-189). Ámsterdam: Rodopi.

Knight, Will (2019). An AI that writes convincing prose risks mass-producing fake news, MIT Technology Review. https://www.technologyreview.com/s/612960/an-aitool-auto-generates-fake-news-bogus-tweets-and-plenty-of-gibberish/

Kogan, Shimon, Moskowitz, Tobias J. y Niessner, Marina (2019). Fake News: Evidence from Financial Markets. En SSRN. https://papers.ssrn.com/sol3/papers.cfm?abstract_ $i d=3237763$

Küng, Lucy, Picard, Robert G. y Towse, Ruth (eds.) (2008). The Internet and the Mass Media. Londres: SAGE.

Laudan, Larry (1981). Realism without the Real. Phiposophy of Science, 48, 19-49.

Lazer, David M. J. et all. (2018). The science of fake news. Science, 359(6380), 10941096.

Levinson, Paul (2012). New new media. Boston: Pearson Higher Education.

Luce, Henry R. y Jessup, John K. (eds.) (1969). The Ideas of Henry Luce, N. York: Atheneum.

Magallón, Rosa (2019). UnfakingNews: Cómo combatir la desinformación. Madrid: Pirámide.

Maras, Steven (2013). Objectivity in Journalism. Key concepts in Journalism. Nueva Jersey: John Wiley and Sons.

Martínez Solano, J. F. (2005). El problema de la verdad en K. R. Popper: Reconstrucción histórico-sistemática. A Coruña: Netbiblo.

McIntyre, Lee (2018). Posverdad. Madrid: Cátedra.

Niiniluoto, Ilkka (1987). Progress, Realism, and Verisimilitude. En Paul Weingartner, y Gherard Schurz (eds.) Logic, Philosophy of Science and Epistemology (pp. 151.161). Viena: Hölder-Pichler-Tempsky.

Niiniluoto, Ilkka (1993). The Aim and Structure of Applied Research. Erkenntnis, 38, $1-21$. 
María José Arrojo

Las Ciencias de la Comunicación desde el realismo científico: El problema de la complejidad $\mathrm{y}$ las noticias falsas (fake news)

ONU (2017). Declaración conjunta sobre Libertad de Expresión y Noticias Falsas, Desinformación y Propaganda. https://www.law-democracy.org/live/wp-content/ uploads/2018/11/mandates.decl_.2017.Spa_.pdf

Pariser, Eli (2011). The Filter Bubble: What the Internet is bidding from you. Nueva York: Penguin Press.

Pauner, Cristina (2018). Noticias falsas y libertad de expresión e información. El control de los contenidos informativos en la red. Teoría y realidad constitucional, 41, $297-$ 318. http://revistas.uned.es/index.php/TRC/article/view/22123/1805

Pérez-Rosas, Verónica, Kleinberg, Bennett, Lefevre, Alexandra y Mihalcea, Rada (2017). Automatic Detection of Fake News. En arXiv, 23 de Agosto de 2017. https:// arxiv.org/pdf/1708.07104.pdf

Popper, Karl (1972). Objective Knowledge: An Evolutionary Approach. Oxford: Clarendon Press, (edición revisada, 1989).

Popper, Karl (1974). Intellectual Autobiography. En Paul A. Schlipp (ed.) The Philosophy of Karl Popper (vol. I, pp. 3-181). La Salle, IL: Open Court.

Renó, Denis (2011). Cinema interativo e linguagens audiovisuais interativas: como producir. Tenerife: Ed. ULL.

Rescher, Nicholas (1998). Predicting the Future. New York: State University Press New York.

Rescher, Nicholas (1999). Razón y valores en la Era cientifico-tecnológica. Barcelona: Paidós.

Resnick, Paul, Ovadya, Aviv y Gilchrist, Garlin (2018). Iffy quotient: A platform health metric for misinformation. School of Information Center for Social Media Responsability University of Michigan, 1(10), 1-10.

Silverman, Craig (2016). Election News Stories Outperformed Real News on Facebook. En BuzzFeed, 16 de noviembre de 2016. https://www.buzzfeednews.com/articlel craigsilverman/viral-fake-election-news-outperformed-real-news-on-facebook

Silverman, Craig y Pham, Scott (2018). These are 50 of the Biggest Fake News Hits on Facebook in 2018. En BuzzFeedNews, 28 de diciembre de 2018. https://www. buzzfeednews.com/article/craigsilverman/facebook-fake-news-hits-2018

Simon, Herbert A. (1996). The Sciences of the Artificial, 3a ed. Cambridge: The MIT Press, Cambridge (1a ed., 1969; 2a 1981).

Simonite, Tom (2013). Software predicts tomorrow's news by analyzing today's and yesterday's. En Technologyreview.com. https://www.technologyreview.com/s/510191/ software-predicts-tomorrows-news-by-analyzing-todays-and-yesterdays/

Small, Gary y Vorgan, Gigi (2009). El cerebro digital. Barcelona: Ediciones Urano.

Subramanian, Samanth (2017). Inside the Macedonian fake-news complex. En Wired, 17 de febrero de 2017. https://www.wired.com/2017/02/veles-macedonia-fakenews/ 
María José Arrojo

Las Ciencias de la Comunicación desde el realismo científico: El problema de la complejidad y las noticias falsas (fake news)

Teruel, Germán M. (2014). La libertad de expresión y la censura en Internet. Estudios de Deusto, 62(2), 41-72. http://revista-estudios.revistas.deusto.es/article/view/250

The Virginia Declaration of Rights, 12 de junio de 1776. En National Archives. https:// www.archives.gov/founding-docs/virginia-declaration-of-rights

Tribunal Constitucional, Sentencia Tribunal Constitucional, 6/1988, 21 de enero, BOE núm. 31, 05/02/1988. http://hj.tribunalconstitucional.es/es-ES/Resolucion/ Show/947

Tuomela, Raimo (1985). Action, Science and Reality. Dordrecht: Reidel.

Tuomela, Raimo (1987). Scientific Realism and Best Explanation. En Paul Weingartner y Gherard Schurz (eds.) Logic, Philosophy of Science and Epistemology. Proceedings of the $11^{\text {th }}$ International Wittgenstein Symposium, Kirchberg, Austria (pp. 196202). Wien: Verlag Hölder-Pichler-Tempsky.

Vosoughi, Soroush, Roy, Deb, Aral, Sinan (2018). The spread of true and false news online. Science, 359(6380): 1146-1151. http://revistas.uned.es/index.php/TRC/ article/view/22123/18051

Wright, Crispin (1987). Realism, Meaning and Truth. Oxford: Blackwell.

\section{Sitios web}

Assembler. Disponible en: https:/jigsaw.google.com/assembler/.

Fact Check Explorer. Disponible en: https://toolbox.google.com/factcheck/explorer

Recorded Future. Disponible en: https://www.recordedfuture.com/about/

The International Fact-Checking Nertwork. Disponible en: https://www. ifcncodeofprinciples.poynter.org

The Trust Poject. Disponible en: https://thetrustproject.org

The Virginia Declaration of Rights, 12/06/1776. Disponible en: https://www.archives. gov/founding-docs/virginia-declaration-of-rights

TinEye. Disponible en: https://tineye.com

Universität Leipzig. Disponible en: https://www.sozphil.uni-leipzig.delinstitut-fuerkommunikations-und-medienwissenschaft/institut/ueber-uns/geschichtel 